\title{
BRASIL, SU GRAN ESTRATEGIA ${ }^{1}$
}

\author{
Carlos Andrés Rodríguez Beltrán \\ María Fernanda Rubio Arrubra \\ Carolina Morales Suárez
}

\section{Introducción}

Con el propósito de realizar un análisis geopolítico de Brasil que haga énfasis en el contexto regional, de manera que sea posible identificar sus intereses, la influencia que ejerce en el escenario latinoamericano y, en particular, la evolución de su política de defensa, consideramos pertinente mencionar algunos aspectos relevantes de este país que se centrarán en la geografía, la geopolítica y la geoestratégica.

Lo anterior, de acuerdo con lo planteado por el autor Jakub J. Grygiel en su libro Great Powers and Geopolitical Change (2006), donde afirma que los estados deben reflejar la geopolítica subyacente en su política exterior o geoestrategia, pues, cuando no lo hacen, el éxito político del Estado e incluso la supervivencia política están en riesgo, y solo los estados que persiguen una geoestrategia que refleje la geopolítica ganan y mantienen una ventaja relativa de su poder.

Así las cosas, empezaremos haciendo una descripción geográfica del Brasil, por ser la realidad física, la geografía — - según Grygiel—, la que describe las características geológicas y los atributos físicos de la tierra, el mar y el aire.

\section{Brasil y su geografía}

Ubicado en América del Sur, con aproximadamente 209.486.000 millones de habitantes (Donadio, 2016), el territorio brasileño posee alrededor de 8,5 millones de $\mathrm{km}^{2}$ de área terrestre y 4,5 millones de $\mathrm{km}^{2}$ de área marítima. El país tiene frontera

1 Este capítulo del libro hace parte del proyecto de investigación de la Maestría en Seguridad y Defensa Nacionales, titulado "Desafíos y Nuevos Escenarios de la Seguridad Multidimensional en el Contexto Nacional, Regional y Hemisférico en el Decenio 2015-2025”, el cual hace parte del Grupo de Investigación Centro de Gravedad de la Escuela Superior de Guerra "General Rafael Reyes Prieto", reconocido y categorizado en (A) por Colciencias, con el código COL0104976. 
con nueve países sudamericanos: al sur con Argentina, Uruguay y Paraguay; al este con el Océano Atlántico; al norte con Venezuela, Colombia, Guyana y Surinam; al oeste con Bolivia y Perú; y un territorio ultramarino de Francia (Guayana Francesa), lo que representa una línea de $16.900 \mathrm{~km}$ de extensión, de los cuales aproximadamente 12 mil corresponden a la frontera de la Amazonia legal.

El litoral brasileño se extiende por alrededor de $7400 \mathrm{~km}$. Por el área marítima brasileña, sobre el océano Atlántico, cruzan importantes rutas de navegación, vitales para la economía nacional. Allí se sitúan las reservas del presal brasileño, de alto significado económico, político y estratégico (Ministerio de Defensa de Brasil, 2012, p. 17).

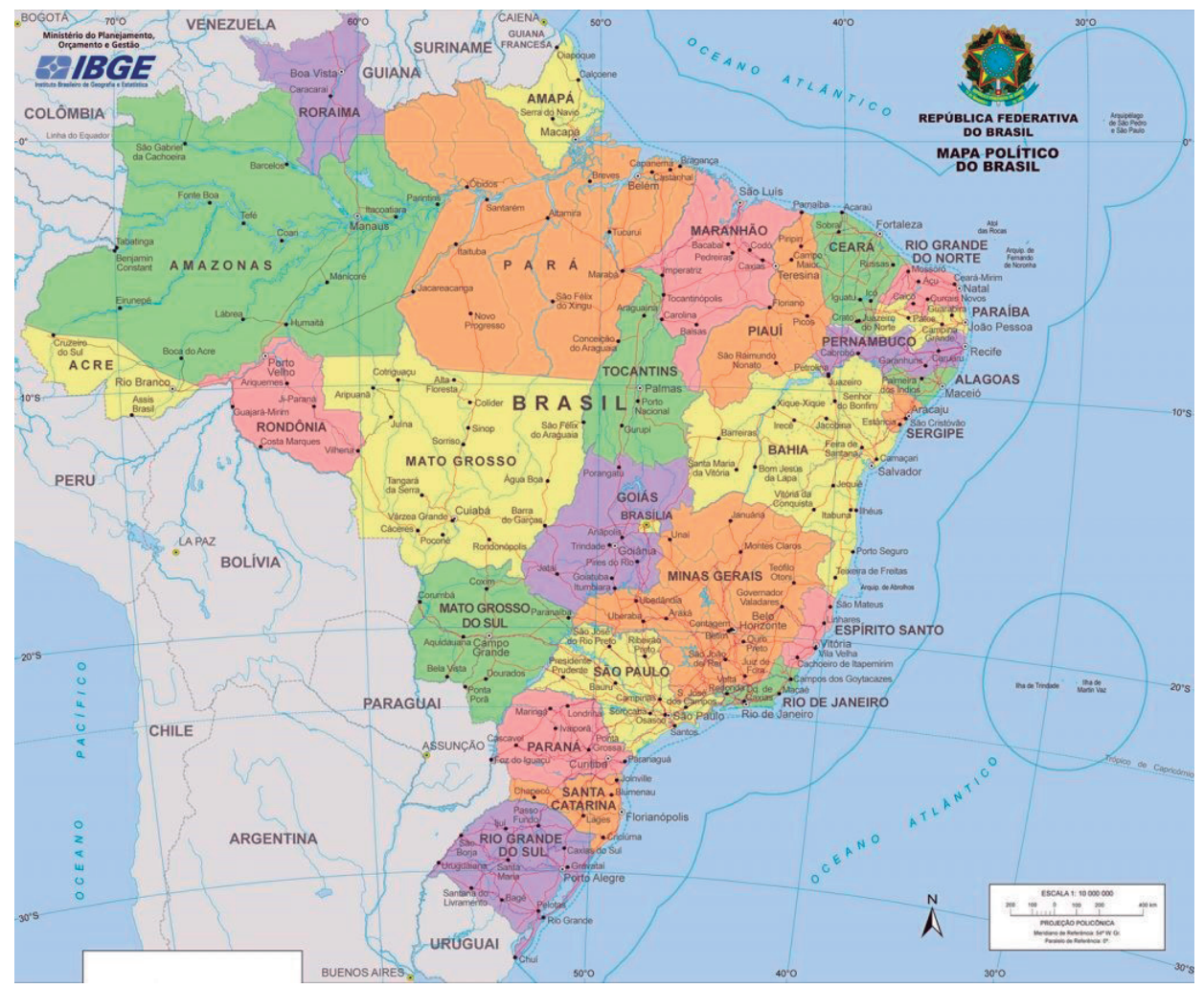

Figura 1. Mapa político de Brasil.

Fuente: Instituto Brasileño de Geografía y Estadística (2018).

El relieve de Brasil cuenta con elevaciones moderadas, tan solo el 0,5\% del territorio cuenta con una elevación mayor a los 1200 metros, mientras el 58,5\% tiene elevaciones inferiores a 200 metros sobre el nivel del mar, razón por la cual 
las formas dominantes de su relieve se consideran mesetas y planicies y no cadenas montañosas ni cordilleras o similares (Ministerio de Defensa de Brasil, 2012, p. 15).

La red hidrográfica de Brasil constituye una de las más grandes del mundo, la cuenca del Amazonas es la mayor y más vasta cuenca fluvial del mundo, con una superficie de $4.787 .717 \mathrm{~km}$ —aproximadamente el 56,25\% del área total de país_- donde desaguan más de la mitad de las tierras de Brasil y además las de Colombia, Perú, Ecuador, Venezuela y Bolivia. Recorre alrededor de seis estados del país y representa un gran porcentaje de las vías de comunicación de la región norte que es navegable en toda su extensión.

\section{Brasil: historia y visión del mundo}

Las características y rasgos físicos por sí solos no dan cuenta de la historia de Brasil, su desarrollo y evolución, por lo que resulta necesario mencionar el siguiente concepto clave: la geopolítica; entendido por Grygiel como el factor humano dentro de la geografía. Es la distribución geográfica de los centros de recursos y las líneas de comunicación, donde se asigna valor a las ubicaciones de acuerdo con su importancia estratégica. La situación geopolítica es el resultado de la interacción de la tecnología ampliamente definida y la geografía, lo que altera la importancia económica, política y estratégica de las ubicaciones. Por lo anterior, es necesario mencionar algunos aspectos que consideramos clave en la historia de Brasil, que resultan de importancia para el análisis geopolítico y para identificar lo que ha sido su geoestrategia.

A diferencia del resto de países de Latinoamérica, Brasil tuvo una conquista, una colonización y una independencia que se podrían catalogar como pacíficas, lo que le permitió ser desde el principio un país unificado y con una clara identidad nacional, a pesar de la gran extensión de su territorio. Un hecho que contribuyó a que la emancipación brasileña no tuviera un carácter violento, como las demás en América Latina, fue el traslado de la familia real de Portugal a Brasil.

En 1808, amenazado por Napoleón e instado por los ingleses, el príncipe regente D. Joao, que sería D. Joao VI, se traslada con su corte y gobierno al Brasil, "hasta la paz general". Esto mudaba todo. La colonia se tornaba de repente una metrópoli que progresaba con una administración que jamás había tenido y se elevaría a la categoría de reino en 1815 .

El primer acto del príncipe fue la apertura de los puertos a las naciones amigas. Luego, tomó muchas otras medidas benéficas para los intereses del Brasil, lo que 
le aseguró una posición de independencia económica que se extendió, finalmente, al campo político, gracias a la creación del Reino Unido de Portugal, del Brasil y Algarbe, en 1815.

En este mismo sentido, Edgar Vieira Posada, en su libro La formación de espacios regionales en la integración de América Latina, manifiesta al respecto lo siguiente:

En el Brasil, la independencia se hizo sin violencia y no se presentó el vacío de poder que ha caracterizado a los países hispanoamericanos. Esto ha contribuido a que no haya caudillismo, puesto que la continuidad en la administración local se mantuvo con Pedro I. Igualmente, en el Brasil se produjo una articulación económica entre los diferentes Estados, a pesar de la extensión de los territorios, lo que facilitó la construcción de un Estado-nación unificado. (Vieira, 2008, p. 64)

De acuerdo con lo descrito por Edgar Vieira Posada, la colonización en Brasil se hizo progresivamente hacia el interior del territorio, ya que no se hicieron descubrimientos importantes de riquezas al principio de la conquista territorial y Portugal no disponía de recursos provenientes del Estado portugués (Vieira, 2008, p. 39). Esto, en palabras de Vieira, hizo que la colonización de Brasil se fundamentara en la producción de productos agrícolas, lo que le permitió ser un territorio en expansión, a diferencia del fraccionamiento característico de los espacios hispanoamericanos (Vieira, 2008, p. 44).

Así mismo, y dada la necesidad de expansión debido al cambio del centro económico, se empiezan a explorar otras zonas más allá del norte, y gracias a que el territorio brasileńo, como ya fue mencionado anteriormente, solo presenta un $0.5 \%$ de elevación, el desplazamiento hacia otras zonas fue, y es, considerablemente más fácil que en el resto de países latinoamericanos, a lo que se añade la ventaja que proporcionan sus ríos navegables, sobre todo el Sao Francisco, que facilitan la movilidad y crecimiento de su población.

Por otra parte, de acuerdo con Halperin, el oro y la minería, en general, cambiarían el destino de Brasil, ya que permitieron poblar el país del norte hacia el sur, y luego hacia el centro, lo que generó centros de economía más allá del azúcar y el oro. Un ejemplo de ello fue el caso de Río de Janeiro en 1720, que para ese entonces era la capital de Brasil, en donde los cultivos tropicales, entre ellos el algodón y el arroz, competían con el azúcar (Halperin, 1977).

Todas estas características geográficas junto con la transición político-administrativa, que fue mucho menos traumáticos que en el resto de Hispanoamérica en la independencia, permitieron que Brasil tuviese una unidad en cuanto a su población, una identidad, a diferencia de lo sucedido en el resto de Latinoamérica, pues 
ninguna adaptación al nuevo orden de cosas fue en ambos aspectos más exitosa que la brasileña; y el imperio terminó por ser, para la republicana América española, un algo escandaloso término de comparación sobre el cual podía medir su propio fracaso. Ese éxito tenía algunos secretos: el viejo orden era en Brasil más parecido al nuevo que en Hispanoamérica; una metrópoli menos vigorosa, y por lo tanto menos capaz de hacer sentir su gravitación; un contacto ya entonces directo con la nueva metrópoli económica, un peso menor de los agentes de la Corona respecto de poderes económico-sociales de raíz local acostumbrados a imponerse, eran todos rasgos que en el Brasil colonial anticipaban el orden independiente. (Halperin, 1977, p. 162)

Es importante resaltar que la consolidación del territorio brasileño y la expansión del mismo fueron una de las principales preocupaciones en la política exterior del Brasil desde 1829, en donde el mayor énfasis de su diplomacia lo realizó en las fronteras.

Una mirada a los mapas del Brasil en las diferentes épocas nos permite advertir algo así como un plan que ha seguido el crecimiento lusitano-brasileño en América. Primero, ocupan las capitanías de la costa, dentro de la línea de Tordesillas, pero apenas se vence el obstáculo de las serranías, las banderas desbordan completamente la línea fronteriza y llegan a internarse en las nacientes del Amazonas y del Orinoco, en busca de esclavos, de caucho y de yacimientos auríferos, diamantíferos y de esmeraldas. En el avance periférico se penetra en los territorios de América Hispánica. Una vez que se logra, en cierta medida, el control del Amazonas, se pretende el del Rio de la Plata (Castro, 1980, p. 34).

Es así como a inicios del siglo XX uno de los principales objetivos de Brasil fue incrementar su prestigio en el mundo y especialmente en América Latina, razón por la cual el canciller de la época, Barón Rio Branco, fortaleció las relaciones diplomáticas de su país con toda América Latina. De forma paralela, se presenta una relación singular entre Brasil y Estados Unidos, en donde la cooperación y el apoyo político y económico por parte del país norteamericano fueron fundamentales para el crecimiento económico y el sueño hegemónico de Brasil por tener influencia y ejercer predominio en el Cono Sur.

En la década de los sesenta, con la llegada al poder del gobierno de Janio Quadros, se lanzó la "política exterior independiente", que da un giro significativo en la política exterior de Brasil, que venía acostumbrada a ir muy de la mano con los postulados de la política exterior de Estado Unidos. Los objetivos de la nueva política exterior brasileña señalaban:

En primera instancia, advertimos la voluntad de no pertenecer a ningún bloque de tinte neutralista o de tercera posición que pudiera enfrentar a Brasil con Estados 
Unidos. Más bien pretendía una cuarta posición original y exclusiva del país del cono sur: era necesario ser pragmático y relacionarse económicamente con todos los países del mundo sin que mediara ningún compromiso político con ellos. (Castro, 1980, p. 69)

De acuerdo con Castro, se resaltan cinco principios fundamentales que guiaron la "política exterior independiente": primero, los nacionalistas buscaron la preservación de la paz; segundo, las Naciones Unidas eran el instrumento por excelencia para resolver las diferencias que pudieran poner en peligro la paz mundial, así como las organizaciones regionales, tales como la Organización de Estados Americanos; tercero, demandaban el fin de la carrera armamentista y el desarme regional; cuarto, los principios de no intervención y autodeterminación de los pueblos debían ser las normas rectoras de las relaciones entre los países. Finalmente, los nacionalistas apoyaban la lucha de las colonias asiáticas y africanas por la independencia (Castro, 1980, p. 70).

Lo anterior, por supuesto, hizo que las relaciones entre Estados Unidos y Brasil se desarrollaran en el marco de la desconfianza mutua, sobre todo porque la política exterior de Brasil pretendía un diálogo diplomático con países de la periferia, además de tener relaciones con la Unión Soviética, el envío de una misión a China, la posición de no compromiso frente a la revolución en Cuba y la política de acercamiento a Argentina, su mayor competencia en la región. (Saín, 2018).

Contrario a las tensiones que se presentaron con Estados Unidos, las relaciones con los países latinoamericanos se desarrollaron en el marco de la diplomacia y la cooperación, como señala Castro (1980) en los siguientes párrafos.

Argentina: para Brasil era sumamente importante la construcción de un nuevo equilibrio regional de fuerzas que giraba en torno a Brasilia-Buenos Aires, de manera que se pudiera contrarrestar la influencia de Estados Unidos en la toma de decisiones de los países latinoamericanos, por lo cual crearon la Asociación Latinoamericana de Libre Comercio (ALALC) en Montevideo, en 1960, esta asociación creó una zona de libre comercio controlada por Brasil, Argentina y México.

Bolivia: siempre ha sido objeto de los deseos expansionistas, en particular de Brasil, por sus riquezas naturales y su posición como heartland geopolítico de Suramérica en el siglo XX, es así como hacia 1899 los brasileños, en virtud del tratado de límites, le ganaron alrededor de $251.000 \mathrm{~km}^{2}$ de tierra.

Uruguay: se acordó seguir una estrategia común en lo referente a los problemas que afectan al continente, en 1963 se firmó un acuerdo relacionado con el desarrollo de la cuenca de la Laguna Merim, situada entre los estados orientales de Uruguay y Rio Grande do Sul. 
Chile: en 1963 se reunieron los presidentes de ambos países y propusieron la creación de una nueva maquinaria para que los productos latinoamericanos fueran más asequibles en el mercado mundial, así como una maquinaria de consulta permanente que pretendía acelerar la integración económica de América Latina.

Paraguay: siempre ha estado dentro de las pretensiones expansionistas y de influencia de Brasil, de hecho, los brasileños construyeron un puente sobre el río Paraná entre las ciudades de President Stroessner y Foz de Iguazú, en 1965, y pavimentaron la carretera entre Foz de Iguazú y los puertos atlánticos de Paranaguá y Encarnación, los cuales fueron declarados puntos importantes de la exportación e importación de Paraguay por el Gobierno brasileño.

Venezuela: fue otra de las prioridades geopolíticas brasileñas por sus recursos petroleros y por su posición privilegiada en la zona del Caribe, en 1973 los dos países firmaron un acuerdo para aumentar las compras de petróleo venezolano, a precio fijo para ese ańo, y constituir una sociedad mixta formada por Petrobras y la corporación Venezolana de Petróleo para la explotación conjunta de los yacimientos de la zona amazónica fronteriza.

Perú: es un punto de interés geopolítico para los brasileños por su posición costera sobre el Pacífico y por sus riquezas naturales; sus relaciones comerciales por el río amazonas fueron bastante buenas.

Es por lo anterior, tal como lo describe Grygiel, que la "geopolítica no es una constante, sino una variable que describe la distribución geográfica cambiante de las rutas y de los recursos económicos y naturales". Sin embargo, tanto la geografía como las líneas de comunicación y los centros de recursos permitieron que Brasil tuviera como una constante la unidad, a diferencia de América Latina.

Además de la identidad, la geografía, las líneas de comunicación y los centros de recursos permitieron que Brasil fuera, y sea todavía, un referente de la economía latinoamericana y mundial, tal como lo describió María Francisca Costa Cholbi en 2014: "el peso económico lo suscribe el ser la sexta economía mundial y disponer de un gran potencial de crecimiento" (Costa, 2014, p. 158).

Desde la década de los noventa, Brasil empieza a participar activamente en el mundo comercial a través de diferentes organizaciones multilaterales y a hacer relaciones comerciales que vendrán acompañadas de un proceso de consolidación en materia de defensa en 1996, de este modo sus gobernantes son consecuentes con la situación geopolítica del momento, como se expondrá más adelante.

Brasil hace parte de la Organización Mundial del Comercio (OMC), desde el primero de enero de 1995, y es miembro del Acuerdo General Sobre Aranceles Aduaneros y Comercio (GATT, por sus siglas en inglés), desde el 30 de julio de 1948, 
de los cuales hicieron parte a su vez, India, China y Sudáfrica, actuales miembros de BRICS, asociación económica-comercial fundada oficialmente en el 2008, que agrupa a los países de Brasil, Rusia, India, China y Sudáfrica. Brasil se convierte en miembro de la OMC como consecuencia de unas negociaciones comerciales en el periodo comprendido entre 1986 y 1994, en la llamada Ronda de Uruguay, y de anteriores negociaciones en el marco del GATT (OMC, 1947).

Así mismo, y como la iniciativa de integración más grande de América Latina, nace en 1991 Mercosur, por medio del Tratado de Asunción. Celebrado en 1994, el Protocolo de Ouro Preto es otro acuerdo fundamental para el bloque, ya que define la estructura institucional del Mercosur y establece las atribuciones y el sistema de toma de decisiones de sus organismos principales. A través del Protocolo de Ouro Preto se atribuyó personalidad jurídica internacional al Mercosur (Ministerio de Relaciones Exteriores de Brasil, 2016).

Ahora bien, esto no siempre fue así, ya que es posible que la Unión Europea haya tardado mucho en estrechar los vínculos con el país. De hecho, el dialogo UE-Brasil se ha realizado sobre todo a través del Mercosur y ha sido el último BRIC en reunirse con la UE en una Cumbre. (Costa, 2014, p. 158)

Así mismo, Costa destaca el papel que Brasil ha logrado durante los últimos años al ser un miembro activo de varios grupos y organizaciones internacionales a nivel diplomático y económico, lo que lo ha llevado a tener, según Costa, una posición privilegiada dentro de América Latina y a ocupar un lugar de liderazgo en América del Sur como portavoz de la región. Esta posición será más adelante discutida, ya que Brasil ejerce cierto liderazgo en la región, pero esto sus vecinos no lo ven de la misma manera.

No obstante, Costa señala que Brasil se percibe como el puente hacia América del Sur, muestra de ello es otro organismo multilateral: Unión de Naciones Sudamericanas (Unasur), que entró en vigor en 2011. Es por esto, que Costa califica a Brasil como

un interlocutor privilegiado para la UE, así como un país fundamental para el éxito de las negociaciones con Mercosur. Además, cuenta con enormes recursos naturales, una amplia diversidad industrial, un vasto mercado interior, un amplio potencial y un mercado repleto de oportunidades. (Costa, 2014, p. 159)

Así las cosas, y de acuerdo con lo expuesto anteriormente, es posible ver cómo la fotografía de las líneas de comunicaciones y los recursos, tomada en la década de los noventa, llevó a los gobernantes de esta década, principalmente a Fernando 
Henrique Cardoso, a consolidar una política de defensa que le permitiera al país asegurar sus recursos naturales y humanos, en razón a los múltiples acuerdos, demostrar la solidez del mismo y hacer hincapié en la capacidad de este de defender sus intereses, línea que seguirán sus predecesores Ignacio Lula Da Silva y Dilma Rousseff.

\section{La política de defensa de Brasil: su geoestrategia}

De acuerdo con Grygiel, la geoestrategia es la dirección geográfica de la política exterior de un Estado; específicamente, la geoestrategia describe dónde concentra un Estado sus esfuerzos al proyectar su poder militar y dirigir su actividad diplomática. La geoestrategia de un Estado no está necesariamente motivada por factores geográficos o geopolíticos. (Dufort, 2017; Serrano Álvarez, 2018).

Aquí resulta fundamental mencionar que Brasil es una República Federativa que adopta el presidencialismo como sistema de gobierno. La división de poderes — ejecutivo, legislativo y judicial— es, en el ordenamiento jurídico brasileño, un principio fundamental y necesario para la promoción del bien de la colectividad (Ministerio de Defensa de Brasil, 2012, p. 17).

Así mismo, es importante resaltar lo dispuesto en la Constitución Política de 1988, donde se establecen varios principios que serán la base de los documentos de defensa publicados a partir de 1996. En la carta magna se define a Brasil como un Estado Democrático de Derecho

destinado a asegurar el ejercicio de los derechos sociales e individuales, la libertad, la seguridad, el bienestar, el desarrollo, la igualdad y la justicia como valores supremos de una sociedad fraterna, pluralista y sin prejuicios, fundada en la armonía social y comprometida, en el orden interno e internacional, en la solución pacífica de las controversias [...]. (Constitución Política de la República Federativa de Brasil, 1988, p. 2)

De tal modo que Brasil, en su propia Constitución, ha exhibido de manera clara y contundente sus intereses nacionales y su política exterior. Un ejemplo de ello es lo expuesto en el Libro Blanco de Defensa frente a lo que Brasil define como la defensa nacional y sus objetivos.

La Defensa Nacional, caracterizada en la Política Nacional de Defensa como el conjunto de medidas y acciones del Estado, con énfasis en la expresión militar, para la defensa del territorio, de la soberanía y de los intereses contra amenazas preponderantemente externas, potenciales o manifiestas, tiene como objetivos: 
1. Garantizar la soberanía, el patrimonio nacional y la integridad territorial.

2. Defender los intereses nacionales y las personas, los bienes y los recursos brasileños en el exterior.

3. Contribuir para la preservación de la cohesión y la unidad nacionales.

4. Contribuir con la estabilidad regional.

5. Contribuir con el mantenimiento de la paz y de la seguridad internacional.

6. Intensificar la proyección de Brasil en el concierto de las naciones y su mayor inserción en procesos decisivos internacionales.

7. Mantener Fuerzas Armadas modernas, integradas, adiestradas y balanceadas, con creciente profesionalización, que operen de manera conjunta y adecuadamente desplegadas en el territorio nacional.

8. Concienciar a la sociedad brasileña sobre la importancia de los temas de defensa del País.

9. Desarrollar la Base Industrial de Defensa, orientada hacia la obtención de la autonomía en tecnologías indispensables.

10. Estructurar las Fuerzas Armadas con relación a capacidades, dotándolas de personal y materiales compatibles con las planificaciones estratégicas y operativas.

11. Desarrollar el potencial de logística de defensa y de movilización nacional. (Ministerio de Defensa de Brasil, 2012, p. 27)

Este libro es publicado y socializado en el 2012, sin embargo, es oportuno mencionar la construcción de otros documentos, leyes y estrategias que permitieron la consolidación de una política clara y contundente en el país. El proceso que se dio para llegar a este punto permitirá evidenciar qué elementos, acontecimientos y relaciones dieron paso a que Brasil sea un referente en diferentes aspectos que lo posicionan como un posible líder regional y una potencia media, de acuerdo con la definición de Carsten Holbraad, quien define a las potencias medias de acuerdo con las siguientes características:

1. Ocupar una posición intermedia en la jerarquía internacional de Estados creando un cierto equilibrio a través del mantenimiento de la paz y la seguridad.

2. Estar situada en el centro de una región y servir de puente o mediadora entre países desarrollados y subdesarrollados.

3. Estar situada entre dos grandes centros de poder antagónicos y servir de mediadora.

4. Estar situada entre distintas civilizaciones y promover el entendimiento entre ellas (Álvarez, 2018). 
Características que podrán ser evidenciadas durante el proceso de consolidación de la política de seguridad en el país, el cual empieza a finales de la década de los noventa cuando, en 1996, en el gobierno de Fernando Henrique Cardoso se publica la "Política de Defensa Nacional" (PDN), en donde por primera vez se deja ver, a grandes rasgos, la posición del país sobre este tema. Si bien el documento no define de manera explícita sus pretensiones y posiciones hacia el exterior, sí plantea un punto de quiebre en donde poco a poco se deja de concebir a los militares como los únicos garantes del cumplimiento de la ley y el orden internos, y los proyecta como la fuerza que tiene su accionar encaminado también a la defensa del país y su territorio contra enemigos externos.

Por otro lado, la crisis económica de finales de los noventa era bastante notoria en casi todos los países sudamericanos y Brasil no era la excepción. Para su segundo mandato, en 1999, Cardoso anuncia una reforma fiscal que no resulta ser de mucho agrado para la sociedad brasileña. Ese mismo año logra promover la creación del Ministerio de Defensa, a través de la Ley Complementaria 97 de 1999, con lo que consigue centralizar y sustituir las acciones de los antiguos ministerios de la marina, el ejército y la aeronáutica. Esta decisión se da en el marco de una lucha histórica entre las tres fuerzas militares, que tenían opiniones diferenciadas y luchaban, cada una por aparte, para sobresalir entre las demás, lo que generó enormes fallas a la hora de tomar decisiones estratégicas y crisis internas en los mandos militares (Barcelona Centre for International Affairs, 8 de octubre de 2016)

Es con la llegada de Lula da Silva a la presidencia, en el 2003, que se dan los primeros acercamientos y discusiones a nivel de todas las instituciones del Estado y la sociedad para la construcción de la Estrategia Nacional de Defensa (END) de 2008, documento que será la pauta y hoja de ruta de la política de defensa de esta nación, y, a su vez, uno de los componentes determinantes a la hora de definir su política exterior y la visión de Brasil hacia la región y hacia el resto del mundo, que será finalmente socializada y puesta en marcha en el segundo periodo de Lula, en el 2008.

Los debates durante los años 2003 y 2004 alrededor de la END se dieron, entre otras circunstancias, por la necesidad de Brasil de reflexionar frente a su posición en el escenario regional y global dados los acontecimientos del 11 de septiembre de 2001, en los que se dieron cambios importantes de la política exterior por parte de Estados Unidos y, por ende, a nivel global, así como su objetivo de empezar a posicionarse como una potencia media sin generar ruido entre sus vecinos.

En el 2010 se da la Ley Complementaria 136 de 2010, que establece en su artículo 9, párrafo 3, la obligación del Poder Ejecutivo de presentar al Congreso 
Nacional, en la primera mitad de la sesión legislativa ordinaria de 2012, la primera versión del Libro Blanco de Defensa Nacional, el cual será uno de los objetos de análisis en este capítulo (Ministerio de Defensa de Brasil, 2012).

Brasil, entonces, afronta los cambios en la política exterior de Estados Unidos luego del 9/11 de una manera que Mónica Hirst (2011, p. 39) define como afirmativa:

Desde sus comienzos, el gobierno de Luiz Inácio Lula da Silva estuvo fuertemente asociado a la idea de cambio, lo que en política exterior trajo como consecuencia la configuración de una etapa afirmativa en la relación con Estados Unidos. De acuerdo con la visión oficial brasileńa, se había alcanzado una etapa de madurez cuyo resultado principal fue la configuración del establecimiento de un diálogo estratégico entre Brasilia y Washington.

De acuerdo con Hirst, esta posición le permitió a Lula iniciar un proceso de liderazgo más allá del nivel regional, lo que permitió la expansión de su proyecto nacional a países fuera de Latinoamérica. Un ejemplo de ello fue ser el líder de la Misión de Estabilización de las Naciones Unidas en Haití (Minustah), en 2003, y empezar a ser reconocido como un país influyente ${ }^{22}$ en la región, lo que a su vez lo llevó a construir una agenda bilateral con Estados Unidos, lo que al final Hirst termina por definir como un modelo de comportamiento brasileño profundizado a partir del gobierno de Lula y en el cual se buscó combinar política regional con intereses globales (2011, p. 43).

Lo anterior es una exposición de algunas de las razones por las cuales Brasil es considerado una potencia media, pues la posición que asumió frente a Estados Unidos es señal de respeto frente a las normas y reglas internacionales, al igual que su participación activa en la formulación y construcción de una agenda bilateral con el país norteamericano, así como su participación en la prevención de conflictos y el mantenimiento de la paz, lo que incluye su participación en misiones de la ONU, como será seńalado más adelante.

De esta forma, y de acuerdo con lo expuesto por la autora en mención, así como por otros académicos como Elodie Brun y Bruno Muxagato, desde el gobierno de Lula se empieza a consolidar un modelo de política exterior enfocado en los siguientes aspectos:

1. Estrategia regional con objetivos más globales.

2 De acuerdo con Carsten Holbraad, una de las funciones que puede asumir una potencia media es contribuir a la prevención de conflictos y el mantenimiento de la paz, lo que incluye la participación en las misiones de la ONU, tener una notable influencia en asuntos puntuales de la agenda internacional y estar en capacidad de definir temas en los foros multilaterales. 
2. Líder regional en América del Sur (estabilidad política y económica).

3. Región como trampolín diplomático.

4. Proyección internacional.

Con base en el presupuesto de que "la creación de un bloque regional poderoso bajo el liderazgo brasileño debe permitir democratizar las relaciones internacionales proporcionando a Brasil beneficios individuales para su proyección internacional" (Hirst, 2011, p. 93).

De esta forma, Brasil empieza a proyectarse hacia el mundo como una potencia media, y la necesidad de repensarse en los ámbitos económico, comercial y político hacen que el sector defensa sea uno de los ejes fundamentales de su renovación, lo que se ve proyectado en la END y en el libro blanco, instrumentos de política pública en los que se hacen explícitos los propósitos de Brasil como nación, sus intereses y los métodos y capacidades que tiene y espera tener para futuros escenarios que se plantean como hipotéticos bien sea de paz, guerra o crisis. (Álvarez Calderón \& Rodríguez Beltrán, 2018).

Por otra parte, autores como Nolte y Flemes plantean el concepto del liderazgo regional de acuerdo a cinco premisas o conceptos generales: 1) ser aceptado por la inmensa mayoría de los países de la región como potencia capaz de representarla; 2) asumir el coste de una superioridad regional, particularmente ayudando a los socios más débiles; 3 ) poseer los recursos materiales (militares, económicos y demográficos), institucionales e ideológicos; 4) ejercer efectivamente una gran influencia sobre todos los sujetos de orden regional; 5) comprometerse con una estrategia a largo plazo con el objetivo de institucionalizar los procesos de integración. Por lo tanto, disponer de los medios necesarios, fijar una voluntad política para ejercer un papel regional determinante y ser reconocido como tal por los Estados vecinos, constituyen tres pilares fundamentales para la obtención del estatus de líder regional.

Es necesario anotar que Brasil, si bien ha ejercido una gran influencia en la región, no se ha logrado consolidar como un líder regional, ya que los países de Suramérica no lo identifican como potencia capaz de representarlos, este criterio es el único faltante para alcanzar su objetivo de ser una potencia y un líder regional.

Con respecto a lo anterior, Brun y Muxagato ponen en el escenario el concepto de hegemonía consensual, a través del cual ejemplifican cómo los gobernantes brasileños han abierto el camino he intentado consolidar una integración regional.

El concepto de hegemonía consensual ha sido desarrollado por Sean Burges, quien se inspira en el pensamiento del teórico marxista Antonio Gramsci (Burges, 2009). La originalidad de la obra del autor reside en poner en un segundo plano el aspecto 
coercitivo en la construcción de una hegemonía (Cox, 1993, p. 92). Sean Burges retoma esta idea para analizar el proyecto de integración bajo el liderazgo brasileño. Puesto que el Estado brasileño no tendría las capacidades de asumir el papel de una potencia hegemónica basada en el hard power, su liderazgo reposaría entonces en la idea de inclusión y de cooptación, a través de la creación de un orden consensual, en el cual la parte dominante formula un modelo de relaciones políticas, económicas y sociales (Burges, 2009)

De igual forma, el libro se destaca como una respuesta a la realidad que vive Brasil en pleno siglo XXI, pues es visible internacionalmente y por tanto necesitará de capacidad militar disuasoria adecuada. Comprometido con la construcción de un orden global más pacífico y próspero Brasil no puede descuidar su defensa. Por ello,

tal configuración compromete sutilmente a las demás partes con la preservación de la hegemonía, ya que las que se adhieren al sistema reconocen el estatus de la parte dominante. Lo que remplaza el aspecto coercitivo en esta situación, es "el costo que deberían pagar los países cooptados si eligen poner fin a su participación en el sistema integracionista promovido por el Estado hegemónico... La hegemonía consensual es entonces el resultado de un acuerdo entre varios Estados que aceptan el predominio de uno de ellos. El líder, también llamado "hegemón", tiene la función de formular, organizar y dirigir este orden consensual, cuidando que los otros actores se sientan incluidos en este proyecto para la defensa de sus intereses respectivos. (Brun y Muxagato, 2012, p. 97).

Es en este contexto que llega Dilma Rousseff a la presidencia, quien continúa con el legado de su antecesor y posiciona a Brasil como un país influyente y de referencia para otras naciones en el mundo.

De hecho, el país tiene el papel de lanzar las iniciativas y de crear los proyectos, particularmente en el marco del proceso integracionista, sosteniendo que solo una América del Sur unida es capaz de defender los intereses comunes de los países de la región. En consecuencia, dos ideas coexisten en el proyecto de integración brasileño durante los gobiernos de Lula. La primera es la construcción de un gran mercado que debe estimular la producción, principalmente de productos de gran valor agregado, y atraer un volumen más importante de Inversiones Extranjeras Directas (IED) procedente del resto del mundo. Además, la integración económica participa en el aumento del peso de los países sudamericanos en las negociaciones extracontinentales, ya que actúan juntos para la defensa de intereses comunes. La segunda idea se explica por el hecho de que la toma de decisiones, teniendo como principio el consenso, evita las acusaciones de manipulación y de dominación en contra de Brasil. El uso de una estrategia agresiva pudiera tener como consecuencia 
la búsqueda por los países menores de un mecanismo regional alternativo (Brun y Muxagato, 2012, p. 97).

Dilma Rouseff, en la introducción del libro de defensa, señala que este representa un escalón en el proceso de consolidación del liderazgo civil y el conocimiento de los asuntos de defensa por parte de la sociedad, y representa un fruto de la evolución democrática de Brasil.

La Política Nacional de Defensa, la Gratius y el Libro Blanco de Defensa Nacional representan marcos históricos en cuanto la afirmación y la difusión de los fundamentos y parámetros de la defensa. La política y la estrategia señalan responsabilidades en la promoción del interés nacional, en particular en los temas relacionados con el desarrollo y la seguridad del país. Muestran la necesidad de fortalecimiento de los mecanismos de diálogo entre el MD y el MRE, en cuanto a la aproximación de sus inteligencias y la planificación conjunta.

\section{Imperativos geopolíticos de Brasil ¿̨líder regional?}

El Libro Blanco de Defensa será, entonces, el medio para definir y exponer los imperativos geopolíticos de Brasil, ya que plasma los intereses del país y su proyección geopolítica en atención a su realidad geográfica, la cual, como ya fue mencionado anteriormente, resulta determinante para un país, pues es la realidad más estable y de menor cambio. Lo que significa para Brasil una diferencia sustancial frente al resto de Latinoamérica, principalmente por lo que acertadamente señalará Edgar Vieira Posada: "El Brasil va a representar la excepción en América Latina en la formación de su espacio territorial, pues será un territorio en expansión, en vez del fraccionamiento característico de los espacios hispano-americanos." (Vieira, 2008, p. 44).

En principio se puede afirmar que uno de los imperativos geopolíticos del país es el control territorial, particularmente el control de la Amazonía, teniendo en cuenta su extensión de 12 mil kilómetros y su importancia en términos de recursos naturales, esto último, considerado el segundo imperativo geopolítico del Brasil.

La Amazonía se encuentra en la zona norte, considerada como la menos densa geográficamente; comparte fronteras con Perú y Colombia, lo que resulta un desafío en términos de control territorial. De acuerdo con Nilson Jobin, ministro de Defensa en ese momento, la realización y publicación del Libro Blanco de Defensa resultaba fundamental, ya que "Brasil tiene la reserva de agua potable más grande del planeta, algunos de los más grandes depósitos minerales, es vecino de 10 países y tiene una frontera de 12.000 kilómetros con la Selva Amazónica” (Hulse, 2011).

Así mismo, el LBD señala que 
la Amazonía representa uno de los focos con mayor interés de la defensa. Lo que se denomina Pan-Amazonia, que equivale a la totalidad de Amazonia en América del Sur, tiene, en números aproximados, el $40 \%$ del área sudamericana y detiene un $20 \%$ de la disponibilidad mundial de agua dulce. La mayor parcela de extensión amazónica pertenece a Brasil, alrededor del 70\%. Brasil afirma su incondicional soberanía sobre la Amazonia brasileña, que tiene más de 4 millones de $\mathrm{km}^{2}$, alberga reservas minerales de distintos órdenes y la mayor biodiversidad del planeta. La cooperación de Brasil con los demás países que tienen territorio en la Pan-Amazonia es esencial para la preservación de esas riquezas naturales. (Ministerio de Defensa de Brasil, 2012. p. 19)

Esta preocupación y consciencia de la importancia del control territorial, por lo que representa la Amazonía y sus recursos naturales, nos lleva a mencionar otro de los imperativos geopolíticos de Brasil, la no injerencia de Estados Unidos, que, como uno de los principales actores del sistema internacional, ha sido en varias ocasiones un obstáculo para el liderazgo brasileño en la región.

Tal como lo señala Silva Guevara (2016), la creación de la Organización del Tratado de Cooperación Amazónica, que, de acuerdo con lo expuesto en el LBD, es una organización que vela por la promoción del uso sustentable de los recursos naturales, sobre todo con los países vecinos, no era sino otra forma de enviar un mensaje a Washington de que los países suramericanos, y sobre todo Brasil, podrían asumir con sus propios recursos económicos y militares cualquier problemática que se presentara, sin la necesidad de la injerencia en estos asuntos por parte de Estados Unidos.

De igual forma, y en esta misma línea de no injerencia por parte del país norteamericano, Brasil defiende su identidad cultural, otro de los imperativos geopolíticos identificados, la cual está muy ligada a la Amazonía y su biodiversidad, por lo que en el LBD señala que la Convención sobre la Diversidad Biológica (CDB) defiende los intereses de Brasil a través de los tres pilares fundamentales de la Convención, a saber: la conservación de la biodiversidad, su uso sustentable y la repartición de los beneficios derivados de la explotación de recursos genéticos.

En la Amazonia colombiana, ecuatoriana, peruana y venezolana, la explotación es aún más primitiva y destructiva; a falta de las reservas de mano de obra que el Nordeste ofrecía en Brasil, debe disciplinar mediante violencia y crueldad aún mayores la más escasa efectivamente disponible; en la búsqueda de rápidos provechos se destruyen los árboles mismos, que en Brasil son solo sangrados periódicamente, pues el mantenimiento del stock está en el interés del siringueiro, que no puede cosechar sino en la zona que le ha sido asignada y sería la primera víctima de la desaparición de los árboles. La ola de explotación destructiva avanza así sobre la 
Amazonia peruana, destruyendo las plantaciones naturales y también el modo de vida de poblaciones neolíticas, arrojadas a participar en la economía del siglo XX mediante el doble estímulo del alcohol y el terror. (Halperin, 1969, p. 310)

En conclusión, el control territorial y los recursos naturales no solo hacen parte de los imperativos geopolíticos de Brasil, sino que forman parte de las características que debe tener una potencia que quiera incidir en el ámbito global y, por supuesto, regional. Al respecto, Susana Gratius señala que parte del poder potencial de Brasil radica en su geografía y su demografía (2007).

Con 185 millones de habitantes y una superficie de 8,5 millones de $\mathrm{km}^{2}$, Brasil es el quinto país más grande del mundo. Más de un tercio de los latinoamericanos son brasileños y la mitad del territorio regional pertenece a Brasil. El país también dispone de importantes recursos naturales (entre ellos el petróleo) y, por la extensión de la selva amazónica es considerado como el pulmón verde del mundo. (Gratius, 2007, p. 9.)

En este sentido, es oportuno volver a la importancia de los recursos naturales que desde la presidencia de Lula da Silva, de acuerdo con lo dispuesto por Raúl Zibecci (2009), fomentaron la firma de convenios para adquirir armamento y equipos de defensa con el objetivo de proteger los recursos naturales más preciados, como la Amazonía, el petróleo y la industria, lo que brindó la oportunidad para que el país se empezara a proyectar como nueva potencia política y militar, tema que será retomado más adelante.

Si bien el control territorial, los recursos naturales, la no injerencia por parte de otros Estados y la identidad cultural son imperativos geopolíticos importantes, las relaciones comerciales marcaron y marcan la geoestrategia de Brasil y la intención de crecer y ser fuerte en términos de capacidad militar, dado que estas relaciones le permitieron abrirse paso en el escenario global como un actor relevante, y en el escenario regional como un referente, al menos, en estos aspectos.

Tal como lo expone Costa, las relaciones estrechas con la Comunidad Europea permitieron la firma de convenios como el Acuerdo de Cooperación Marco CE-Brasil, que abarca aspectos como la cooperación en materia de comercio, inversión, financiación, ciencia y tecnología, transporte, medio ambiente, desarrollo social, lucha contra las drogas e integración regional (Costa, 2014, p. 160). "El establecimiento en 2007 de la Asociación Estratégica UE-Brasil viene a reconocer el papel de Brasil como actor global en las relaciones internacionales, tanto desde el punto de vista político como económico y comercial y de la cooperación" (Costa, 2014, p. 161). 
En este punto, y de acuerdo con lo ya expuesto, es pertinente volver a resaltar la importancia del Mercosur, ya que este mercado y los acuerdos comerciales generados a partir de esta iniciativa permitieron que Brasil adoptara una posición relevante y que volteara la mirada hacia su región, ya que este sería el inicio de la integración, al menos económica, de América Latina, en cabeza del país, tal como refiere Gratius (2007).

No obstante, y a pesar que Brasil en términos económicos y comerciales cumple con las características de una potencia media - es la décima economía más grande del mundo y representa más de un tercio del PIB regional— su crecimiento económico es mínimo (Gratius, 2007) y actualmente ha tenido un crecimiento inferior a los demás BRICS, además, enfrenta una crisis política relacionada con corrupción que impide que sea un referente en su región y globalmente su imagen puede llegar a ser no muy favorable.

Así las cosas, resulta oportuno ahondar en su política de defensa, ya que esta es parte fundamental de su geoestrategia, por lo que consideramos pertinente empezar con lo expuesto por Celso Amorin, ministro de Defensa brasileńo en 2011, quien señaló en la firma de un acuerdo de cooperación con su homólogo peruano en los sectores aeroespacial y naval, en el marco de la defensa y la seguridad, que: "Para la región, cooperación, fuera de la región, disuasión" (Guevara, 2011, p. 25).

Brasil es uno de los países más influyentes del sistema internacional, cuenta con las capacidades económicas, militares y políticas para ser un tomador de decisiones que afecten el statu quo, en ese sentido, es necesario reflexionar sobre su política de Defensa y es de suma importancia generar acciones coordinadas e integrales junto a sus vecinos.

\section{Referencias}

Álvarez, C. (2018). Geopolítica Seguridad Global y Regional. Teorías Modernas (tesis de maestría inédita). Escuela Superior de Guerra "General Rafael Reyes Prieto”, Bogotá, Colombia.

Álvarez Calderón, C., \& Rodríguez Beltrán, C. (2018). Ecosistemas criminales. Revista Científica General José María Córdova, 16(24), 1-30. https://doi.org/10.21830/19006586.352

Donadio, M. (2016). Atlas Comparativo de la Defensa en América Latina y Caribe/Edición 2016. Buenos Aires: Red de Seguridad y Defensa de América Latina (Resdal).

Brun, E. y Muxagato, B. (2012). El proyecto internacional brasileño (2003-2010): Intenciones regionales y proyección global vía las relaciones Sur-Sur. Anuario americanista europeo, 10, 2221 3872.

Castro, P. (1980). Fronteras abiertas expansionismo y geopolitica en el Brasil contemporáneo (1ª ed.). México: Siglo Veintiuno. 
Constitución Política dela República Federativa del Brasil(1988). Recuperado dehttp://www2.congreso. gob.pe/sicr/cendocbib/con4_uibd.nsf/DB0906178F38C78105257D9A006D1B77/\$FILE/ Constituci\%C3\%B3n_Brasil.pdf

Costa, M. (2014). Las Relaciones Comerciales de la ue con Brasil. Revista ice, 3054. Recuperado de http://www.revistasice.com/CachePDF/BICE_3054_157-168_3B9BB9DBBF79DAC66F34 FE3810919E4E.pdf.

Da Silva, G. (2011). Brasil, opciones estratégicas de una potencia emergente para afirmar su liderazgo mundial. oasis, (16), 11-29. Bogotá: Universidad Externado de Colombia.

Dufort, P. (2017). La influencia de la comprensión cambiante del poder sobre la estrategia: un ensayo genealógico. Revista Científica General José María Córdova, 15(19), 29-81. https://doi. org/10.21830/19006586.83

Hulse, J. (2011). El Libro Blanco del ejército brasileńo guía las prioridades de defensa a futuro. Diálogo Revista Militar Digital.

Ministerio Nacional de Defensa (2008). Estrategia Nacional de Defensa. Recuperado de www.defesa. gov.br

Ministerio de Relaciones Exteriores

Gratius, S. (2007). Brasil en las Américas: ¿Una potencia regional pacificadora? Madrid: Fundación para las Relaciones Internacionales y el Diálogo Exterior (fride).

Grygiel, J. (2006). Great Powers and Geopolitical Change. Johns Hopkins University Press.

Halperin, D. (1977). Historia Contemporánea de América Latina. El libro de bolsillo. Historia Alianza Editorial.

Hirst, M. (2011). Las relaciones entre América Latina y Estados Unidos en los tiempos de la pos-Posguerra Fría. En D. Wollrad., G. Maihold y M, Mols (eds.), La agenda internacional de América Latina: entre nuevas y viejas alianzas (pp. 31-48). Buenos Aires: Nueva Sociedad.

Justo, M. (2016). ¿¿Cuáles son los 6 países más desiguales de América Latina? bbc Mundo. Recuperado de: http://www.bbc.com/mundo/noticias/2016/03/160308_america_latina_economia_desigualdad_ab.

Ministerio de Defensa de Brasil (2012). Libro Blanco de Defensa Nacional. Recuperado de https:// www.defesa.gov.br/arquivos/estado_e_defesa/livro_branco/lbdn_esp_net.pdf

Ministerio de Relaciones Exteriores de Brasil (2016). Recuperado de http://www.itamaraty.gov.br/es/

Saín, M. (2018). ¿Militarización del control del narcotráfico en Argentina? Revista Científica General José María Córdova, 16(24), 61-82. https://doi.org/10.21830/19006586.366

Serrano Álvarez, J. M. (2018). El paradigma de la guerra en el siglo XX. Revista Científica General José María Córdova, 16(23), 23-42. https://doi.org/10.21830/19006586.305

Organización Mundial del Comercio (OMC) (1947). Acuerdo General sobre Aranceles Aduaneros y Comercio (GATT). Brasil: Ministerio de Relaciones Exteriores. Recuperado de https://www. wto.org/spanish/docs_s/legal_s/gatt47.pdf.

Guevara, S. (2016). Intervencionismo y medio ambiente: el caso de la Amazonía brasileńa. Revista de Relaciones Internacionales, Estrategia y Seguridad. 12(1). pp.209-236. DOI: http://dx.doi. org/10.18359/ries.2470

Vieira, E. (2008). La formación de espacios regionales en la integración de América Latina. Bogotá: Pontificia Universidad Javeriana. 